\title{
How Mathematical Literacy teachers facilitate mathematisation in modelling situations
}

\author{
Hanlie Botha and Sonja van Putten*
}

University of Pretoria, Pretoria, South Africa

*Correspondence to Sonja van Putten email Sonja.vanputten@up.ac.za

\begin{abstract}
Mathematical Literacy (ML) is a compulsory subject in South Africa for those learners who choose not to do mathematics to Grade 12 level. ML is designed to enable a learner to become a self-managing person by providing opportunities to analyse and solve real-life problems, through the mathematisation of contextual situations. The subject thus lends itself to modelling situations in which a mathematical problem involves a process of transferring between the mathematics and reality. This article reports on an explorative case study conducted with four ML teachers who were required to facilitate mathematisation in modelling situations in their classrooms. Schukajlow's three categories of mathematical problems were applied to identify the type of problems the ML teachers used. The strategies used by the teachers in facilitating the mathematisation process were analysised using a framework in which a real-life problem is explored, a model is formulated, analysed and the result of its application is interpreted and validated in terms of the context. This study focuses on the horizontal mathematisation that lies between context presentation and model formulation. Classroom observations were used to collect the data and a deductive analysis approach was implemented. The study revealed that some teachers find it difficult to go beyond intra-mathematical problems and that the modelling process in general, and the function and direction of mathematisation in particular, are not well understood. The resistance to the use of real-life contexts in the ML classroom was based on disinterest in the context itself or an inability to relate to the real-life situation. We make the recommendation that the process of mathematisation in a modelling situation must be taught systematically and deliberately in pre-service mathematics teacher training programmes.
\end{abstract}

Keywords mathematical modelling, horizontal mathematisation; mathematical literacy; classroom practice

\section{Introduction}

After a mathematics lecture to student teachers in which the major part of the lecture was devoted to the application of mathematical principles to real life scenarios, one of the student teachers came to us and asked very politely whether it was not perhaps possible to change the context so that the students were better able to understand what they were supposed to do. $\mathrm{He}$ made it clear that neither the context nor the application of mathematics to the context made sense to many of the students in the class. Upon enquiry, we discovered that the students found engaging with the context particularly difficult - instead they wanted to go directly to the actual sums involved, without going through the mathematising process of the real-life situation. It 
seemed as if the students were far more comfortable with "the memorisation of mathematical routines" (Biccard \& Wessels 2017, p. 61), than with mathematical sense-making which according to Biccard and Wessels (2017), should be encouraged. Yet, the student teachers with whom we were working had in theory experienced modelling situations in the mathematics classroom during their high school careers. Why then, the resistance to modelling and mathematisation in particular? Surely the implementation of familiar and unfamiliar contextual problems would have been part of their mathematics classroom experiences. Of particular relevance to mathematics education at high school level, is contextual modelling, which, according to Kaiser and Sriraman (2006), is subject-related and deals with information processing. This made us think about how modelling takes place in South African secondary schools, in particular in a subject like ML, where modelling plays a significant role.

Mathematical literacy is defined differently in various countries around the world. It may be called quantitative literacy or matheracy, or it may be referred to as numeracy (Rosa \& Orey, 2015). Internationally, people may be seen as mathematically literate if they can apply mathematics to practical problems that are part of daily living routines and can arrive at a solution (Jablonka, 2003). In South Africa, the term is also applied to a subject taken by learners in Grades 10-12. According to the requirements of the South African Department of Basic Education (DBE) (2011), mathematics in some form is compulsory for high school learners in Grades 10 -12. The subject ML was implemented in 2006 to provide an alternative to pure mathematics for those learners who are unable or unwilling to continue with mathematics. The subject lends itself to modelling (Brown \& Schäfer, 2006) because it is intended to make learners comfortable with "the increasing mathematisation of all social domains" (Gellert, 2004, p. 172). The ML curriculum aims to build a bridge between school and society by bringing authentic and relevant real-life contexts into the classroom in order to prepare learners to meet the demands of the future (DBE, 2011), thus breaking through "the poor permeability of the membrane separating classroom and school experience from life experience" (Freudenthal, 1991, p. 17).

\section{Objectives of the study}

Modelling is not easy for teachers (Cai et al., 2014) because it can be quite unpredictable (Freudenthal, 1973). The words of Cai et al. (2014, p. 148) are true for mathematics teacher preparation in South Africa: "In general, teachers' initial and in-service training as well as curricular contexts of schooling have not readily provided opportunities to make mathematical modelling an integral part of daily lessons". Considering that formal training in the use of mathematical modelling in the secondary school classroom is not something that ML teachers would have received but noting that the ML curriculum foregrounds the use of mathematical modelling, our research interest in this area was piqued: What types of mathematical problems do ML teachers use? How is the mathematisation handled within the modelling process?

\section{Modelling}

While there are several definitions for modelling, the foremost thinkers in this field simplify the definition to indicate the relationship that can be established between the real world and mathematics. According to Cirillo, Pelesko, Felton-Koestler and Rubel (2016), mathematical modelling can be seen as "linking classroom mathematics to something from everyday life that is not inherently mathematical" (p. 3). In the ML Curriculum and Assessment Policy Statement 
(CAPS) of the DBE (2011), the notion of modelling is defined as "elementary mathematical concepts and skills that are relevant to making sense of numerically and statistically based scenarios that are faced in the everyday lives of the individual" (p. 8). This implies the use of contextual problems that "elicit student thinking - to reveal bases of understanding that can be built upon" (Schoenfeld, 1983 p. 407). For the purpose of this study with ML as its context, we refine this definition by bringing in two aspects mentioned by Blum (2002): modelling has direction - it moves from reality to mathematics; and modelling is a "process leading from a problem situation to a mathematical model" (emphasis added) (p. 153). According to Stacey (2011), mathematical modelling involves three processes: formulating, solving, and interpreting. Brown and Schäfer (2006) use the terms formulation, analysis, interpretation, and consolidation to describe the same cyclical processes. These processes, we believe, lie at the very foundation of the work of the teacher, who leads the learners from the real-life situation to the application of appropriate mathematics. However, in this study we focus on one aspect of the modelling processes, namely, the exploration of the context and the formulation of the model.

\section{Mathematical Literacy and mathematisation}

The South African conceptualisation of mathematical literacy is dependent on the mathematisation of contextual situations. This is closely associated with mathematical modelling (Stacey, 2011), since, in the words of Blum (2002), "we use applications and modelling to denote any relations whatsoever between the real world and mathematics" (p. 149). Skovsmose (2013) speaks of mathematisation as mathematics in action, which is vital because mathematics is ubiquitous. Mathematising, simply put, is "translating from the real world to the mathematical world" (Biccard \& Wessels 2011, p. 378). Treffers (1978) and Gravemeijer (1994) speak of horizontal and vertical mathematisation where the vertical mathematisation has to do with reorganisation and progressive structuring within the mathematical system, or as Freudenthal (1991) puts it, "moving within the world of symbols" (p. 24). Specifically, this study looks at horizontal mathematisation as defined by Treffers (1978) when he speaks of such mathematisation as involving the "effort to schematise a problem till a problem statement is created that can be solved using mathematical methods" (p. 79). We see this as involving an "understanding of the contextual problem in mathematical terms" (Biccard \& Wessels, 2017, p. 63). It is this understanding which is expected in ML, where, according to Rosa and Orey (2015), "this approach allows students to look for mathematical ideas embedded in the activities they develop in their daily routine, which helps them to enhance their numeracy skills, abilities and competencies" (p. 591). According to Blum (2002), "mathematizing real situations as well as interpreting, reflecting and validating mathematical results in reality are essential processes when solving literacy-orientated problems" (p. 151). Biccard and Wessels (2017) refer to this mathematising process as the construction by learners of "formal mathematical concepts out of their own informal concepts" (p. 61).

\section{Conceptual framework}

Since we are investigating the way ML teachers handle a modelling situation, we will look specifically at the way the teacher brings real-life problems into the classroom-life of the ML learner (modelling) through the use of authentic and relevant problems (DBE, 2011). To this end, we have developed a conceptual framework which is an integration of the work of various 
researchers referred to earlier. Schukajlow et al. (2012) describe three categories of mathematical problems. Those without any connection to the real world they call intra-mathematical problems. A problem where a particular mathematical topic is camouflaged in a real-life contextual setting, they call dressed-up problems. The third type of problem, i.e. modelling problems, involves "transfer processes between reality and mathematics" (p. 219-220). In this study, we identify the problems used by the ML teacher in a modelling situation according to these three categories. Then we specifically analyse the horizontal mathematisation process facilitated by the teacher, according to the first component of Blum's (2002) approach to mathematical modelling. We also comment on the observability of the remaining components of Blum's model (2002). He describes three components of the modelling process: exploration of the context and formulation of the model; analysis of the model; and interpretation and validation of the conclusions in terms of the context. This framework is rooted in Polya's (1957) steps in the problem solving process: making sense of the problem; developing a model to solve the problem; implementing the model; and reflecting on the results.

\section{Research methodology}

A qualitative research approach involving an exploratory case study was used as research design. The research sample consisted of four Grade 11 ML teachers who varied in experience from one to four years of teaching ML. Four schools in the city of Pretoria were selected: three state schools and one private school. The data were collected by means of three classroom observations per teacher which were videotaped and transcribed verbatim. The teachers were requested to present lessons in which modelling situations were used to demonstrate their facilitation of the mathematisation process.

ATLAS.ti 6 was used to analyse the raw data according to the conceptual framework. The data were analysed deductively, by determining whether the problem was purely mathematical with no context, lightly disguised within a contrived context (dressed-up), or modelling in which a transition specifically in the direction of real-life to mathematics can be seen. The teachers were informed in writing that their performance in class would not be reported to their superiors, and the interpretation of the data were both member and peer checked. Ethical clearance for the study was granted by the Ethics Committee of the University of Pretoria as well as Gauteng Department of Education. The teachers and principals of the schools signed letters of consent to be part of the study. Pseudonyms are used to protect the teachers' identities.

\section{RESULTS}

The data gathered in the lessons of each of the four teachers are presented and discussed per teacher. The findings are presented according to the conceptual framework. Each of the teachers used their own discretion as to what they taught, both in terms of modelling and mathematical content, with a view to allowing the learners to master the requirements of the curriculum.

\section{Lizzy}

Lizzy grew up in Nigeria, is 30 years old and holds a BTech Management Accounting degree including two years of Financial Mathematics. This degree did not include any Mathematics Education or Mathematics Methodology courses. As a novice teacher at an under-resourced 
independent inner city school with 350 Black South African learners, she has taught ML for two years, but without teaching any mathematics per se. Her teacher-centred teaching style was characterised by her presenting a monologue to the class with very limited teacher-learner interaction and no learner-learner interaction. Lizzy's three lessons were focussed only on mathematics in general, and conversions in particular; no context was mentioned.

\section{Findings}

Lizzy's lessons were presented in an entirely behaviourist style and modelling was not part of her practice. Instead, simply memorising mathematical routines and substituting numbers in given formulae were expected of learners. She taught using only intra-mathematical problems. Measured against our framework, it can be seen that horizontal mathematisation did not take place. It was clear that Lizzy did not recognise the teaching of ML as a modelling situation.

\section{Richard}

Richard, a Tswana speaking South African, is also a novice teacher in his second year of teaching ML. He has taught one year of Grade 10 Mathematics. He is 24 years old and completed his BEd degree with Mathematics as major. He teaches at an under-resourced inner city state school of 500 Black South African learners. His style was also teacher-centred and in general, he did not encourage the learners to participate actively in the lesson.

Richard's first two lessons were about solving simultaneous equations and the third was about data handling. In his first lesson, he used no contextual problem of any kind. Instead, he had the learners work through a series of intra-mathematical problems. His second lesson, however, was different.

His second lesson about simultaneous equations he introduced as follows:

Where can we solve things simultaneously? OK, remember we are approaching the Election Day and we need to support the campaign. Don't you think the results can be solved simultaneously, how? Remember he has to sit on the parliament and the province and we have nine provinces, né? Remember for the vote of the 18th they are going to take the result because remember people voted for this particular party, or this party or organisation. They are going to add all those results and what information do you think we can get out of that? We can convert it into equations and solve simultaneously. That will tell us how many positions that party is going to get in...? Parliament, né? So you see we solve it simultaneously. Once you know the number of how many people voted for the party you know how many will sit in parliament. [sic]

From this point on, he dealt purely with the mechanics of simultaneous equations (this is not in the ML curriculum), making no link between the example he used to introduce the lesson and the actual mathematics in the sums.

His third lesson followed the same path. This lesson was about data handling: measures of central tendency. He introduced the lesson with some information about data collection in general:

What is data handling? OK, that is when you go out and gather information or doing research or go and investigate. OK, now you have to go and do research which means it's part of? Collection of data. So you go out and collect data. Once you have collected data, 
what do you do? You summarise it or you analyse it and then after that you present it... If you don't have a target, you cannot go out and do research. If for example you can investigate how many young people are studying. You can't go just on the street and collect data there, it means you have to select schools. For example on the streets we have street kids that are not part of the school, but they are part of the street. Once you have a target, you identify your target. For example, if you want to know about males and females. OK, come here (calling a boy to the front to stand next to him). Is this guy a male or female? (The learners answer: male). OK, go and sit down. I want to ask you which features identify him, characterise him as a male? (Learners gave some answers). So even if you go to this thing of mathematics or mathematical literacy, you need to have a picture of it. OK now, we start with the mean. What is meant by mean? What comes to your mind? [sic].

Once again his lesson moved from the clarification of the concept and some contextual references like "street kids", directly to the mathematical content, without the formulation of a model. He did not refer back to either the "street kids" or the boy he used as an example of data collection about gender.

\section{Findings}

In his first lesson, Richard only used intra-mathematical problems. However, in the two subsequent lessons, Richard attempted to introduce a context as an example of where the mathematics that he wanted to employ, could be used, but failed to make it meaningful. Therefore, according to our framework, the contexts he used in the second and third lessons cannot quite be classified as dressed-up problems because no problem was camouflaged inside the contextual setting. He did not guide the exploration of his examples to lead to the formulation of a model. In fact, the contextual situations that he used were left completely disconnected from the mathematical exercises that followed. He attempted to involve the learners in his discussion of where the mathematics they were doing could be applied, but according to Blum (2002), modelling has direction, moving from reality to mathematics, and this direction was reversed in Richard's lessons. He used a context to explain the application value of the mathematics. The rest of each lesson did not include analysis or interpretation and validation because modelling as per Blum's (2002) definition, did not take place. Instead, the learners' involvement was largely based on questions such as: "What is meant by mean?" A learner replied: "Bigger, smaller" and Richard replied: "Average. It's average. And once you see that average, you see lots of numbers adding each other and dividing by the number of them. That is the picture you must have". The learners showed no interest in the contexts discussed in the introduction, but were concerned only about the mathematical solutions of the given sums.

\section{Ruth}

Ruth, also a Tswana speaking South African, is 42 years old, and holds a BEd degree which included Mathematics and Methodology of Mathematics. She also holds a BEd Honours degree. She has taught mathematics for seven years and ML for four years. She teaches at a relatively well-resourced multicultural state school with 908 learners. She varied between a teacher- and learner-centred style, and she encouraged interaction with her, but not specifically amongst the learners themselves. 
The three lessons observed in Ruth's classroom were each about a different topic. Her first lesson dealt with solving quadratics (this is not in the ML curriculum), the second with graphing parabolas (this is not in the ML curriculum) and the third with data handling. The first two lessons involved no mathematising of a context at all. Only intra-mathematical problems were done. However, in the third observed lesson she described a study (from the textbook) in which 540 learners were questioned about the music instruments they prefer. Before the task was introduced, she said:

Remember that your pie chart is a circle graph which is $360^{\circ}$. If you have data that is represented from a table on this, remember you are going to divide by the total number and then you are going to multiply by 360 .

She wrote the problem on the board and learners copied it in their books: How many learners preferred the keyboard? How many learners preferred the drums? How many learners preferred the trumpet? How many learners preferred the guitar? She then talked them through all the information of the problem and asked, with reference to a quarter circle in the pie chart: "Now we want to know how many learners are represented on this pie chart who prefer the keyboard. So what do you do?" A learner answered: "I will say $90^{\circ}$ divide by 540 times 360 ". Ruth wrote it on the board and asked the learners whether it was right or wrong. Most of them were unsure, but many regarded it as correct. Ruth replied: "Remember 90 degrees is the fraction of $360^{\circ}$, so what you do is $90^{\circ}$ divide by $360^{\circ}$ times $540^{\prime \prime}$. She copied the pie chart presenting this data from the textbook onto the board. Her sketch was unrealistic in terms of how the sectors looked, for example, the $60^{\circ}$ sector (for trumpets) was larger than the $140^{\circ}$ one (for guitars). The learners were then required to complete the sums.

\section{Findings}

In two out of the three lessons, Ruth used no modelling of any kind, pure mathematics lessons were conducted using intra-mathematical problems. In the third lesson, she discussed a dressedup problem, drawing elements from the real-life situation into mathematics. She explored the context only with a view to providing the appropriate mathematical model, but not by connecting the problem to the learners' lives. She gave them the necessary mathematical information (although not always correct) to solve the problems they were required to do, and did not allow them to interpret their solutions in terms of the real world. The model that was formulated was thus teacher-guided and did not continue into analysis or interpretation. She did not return to the context of the problem when the learners had completed the task. Although she tried to make the lesson interactive, unfortunately only a few learners in the front of the class were willing to participate. Often the boys in the back row withdrew from the lesson by lying on their arms or talking to each other. There was very little evidence of learner interest or involvement in the contextual setting.

\section{Cynthia}

Cynthia is a 44 year old Afrikaans speaking South African and holds a Higher Education Diploma: Senior Primary with Mathematics and Mathematics Didactics. She has taught mathematics for eight years and ML for three. Her school is also multi-cultural with 1300 
learners, and is well-resourced. Her teaching style also varied between teacher- and learner centred, and she facilitated interaction in her classroom with a view to creating whole-class discussions.

Cynthia used real-life scenarios in all three her lessons. The problems were based on the diversity of learners' interests and experiences. In her lesson on time, she used parking tariffs as context and in her lesson on interest, she elaborated on the idea of buying a house and the implications thereof on a family's budget. She invited thought around the issue of buying a house, for example: "Let us talk a little about why a person would rather wait to buy a house until he increased his deposit". She also asked learners to explain their answers and views and asked questions such as: "Why did you decide on compound interest?"; "Show me where you get that"; and "Yes, but what does it actually mean?"

Her strategy is exemplified in her third lesson on perimeter, area and volume, in sketching the following modelling problem: "If I give you the task of painting the class, you have to determine the area you need to paint". She then asked how the learners would do that. A learner suggested multiplying length and breadth, to which the teacher replied: "No, because then you are going to calculate the area of the floor". Cynthia continued: "It will be two times the length times height and two times the breadth times height" and then asked how they would be able to look through the windows if they were to paint the length times the height of all the walls. A learner replied: "You have to calculate the windows". Cynthia: What do you need to determine regarding the windows?" Learner: "The area". Cynthia: "Yes, I am going to calculate the area of the windows and the door and what will I do with that answer?" The learners chorused: "I subtract it". Cynthia: "So there you are, we subtract it from the total area of the walls". In this manner she continued to lead them to formulating a model. In dealing with volume, Cynthia worked through a problem in the textbook about cooking rice in a large pot. She guided them through the questions and discussed the reality of the pot's volume being 62.8 litres and how large such a pot must be.

\section{Findings}

Cynthia used both dressed-up word problems (e.g. cooking a large pot of rice) and modelling problems (e.g. buying a house; painting the classroom) to bring contextual situations into the classroom. She led the learners through exploration of the context and formulation of the model without just presenting them with the appropriate mathematical procedure. She helped them to analyse the model by, in the case of the painting problem, pointing out the pitfalls in their modelling. She helped them to interpret the solutions, for example in linking the calculated capacity of the pot with the reality of such a big pot. The learners appeared interested and the whole class willingly participated in the discussions that ensued. Her interactive strategy involved much questioning and accessing the learners' experiences of real-life situations similar to the one under discussion. She allowed enough time for the learners to respond and then used their ideas to provide scaffolding to assist them in developing conceptual understanding.

\section{Discussion}

The first research question asked specifically what type of mathematical problems ML teachers use. We found that intra-mathematical problems were most commonly used alongside of some 
dressed-up problems. Modelling problems per se were only used by Cynthia. The second question referred to the handling of horizontal mathematisation within the modelling process. Only Ruth and Cynthia demonstrated successful or partially successful modelling where a reallife situation was explored, a model formulated and analysed and the results interpreted and validated. However, as far as horizontal mathematisation is concerned, we found that this process was really only demonstrated by Cynthia.

\section{Mathematical problems}

Modelling did not occur in Lizzy's class: she only used intra-mathematical problems. Apart from the intra-mathematical problems Richard used in Lesson 1, he attempted modelling problems by presenting real-life situations where the mathematics at hand could be used, but also without any mathematising of the real-life situations. In fact, he used intra-mathematical problems with a contextual illustration. Ruth used intra-mathematical as well as dressed-up problems, but did not allow the learners to formulate or interpret any models. Only Cynthia actually used modelling problems in which learners were guided to formulate and analyse the model as well as reflect on its meaning and interpretation. It is a fact that the integration of real-life contexts with mathematical applications in a modelling situation is a prerequisite in the ML curriculum (DBE, 2011). According to Zuga (1992), learners will be prepared to perceive and understand the issues they will be confronted with as adults if the contexts are real and authentic. What Rosa and Orey (2015) have to say about numeracy is equally applicable to ML in the South African context:

Numeracy is then defined in terms of the capacity of individuals to perceive how mathematics is used in their own socio-cultural contexts, to apply mathematical ideas, procedures, and practices in distinct contexts, and to use mathematics critically and to reflect on its consequences. (p. 588)

However, what we observed was that the contexts that were used in Richard's and Ruth's lessons did not generally spark the interest of the learners. The learners seemed to be more interested in and concerned about the sums than the contexts in which they were presented. Cynthia's class however, was an exception: her learners were engaged; they questioned; they thought; they responded. The contexts she used seemed to have been directly related to their own experiences.

\section{The mathematising process}

In terms of our conceptual framework, the horizontal mathematising process involves context exploration and formulation of the model within the modelling cycle, i.e. "understanding of the contextual problem in mathematical terms" (Biccard \& Wessels 2017, p. 63). We found that facilitating real-life problems into mathematical terms was either not done at all (in the case of Lizzy) or was heavily guided to the extent of providing the mathematical model (in the case of Ruth). In Richard's case, he misunderstood the direction that mathematisation should take and instead of guiding the real world into the world of mathematics, he showed how the world of mathematics can be used in the real world. Cynthia, by contrast, allowed the learners not only to explore the context, but to, with guidance, formulate a model according to their understanding. She then guided the learners through the interpretation and validation of their results. Thus, it was clear that Cynthia was able to follow the mathematising process and was able to take the learners through the remaining two components of the modelling process by allowing them to analyse and interpret their results. 


\section{CONCLUSION}

The value of modelling in mathematics education has been established and should not be neglected in any classroom where learners are required to recognise the mathematisation of the world in which they live. Through the process of mathematisation the learner is able to engage with the context and its relevance to the real world, with a view to creating a model for the solution of the problem that is presented, and ultimately interpreting and validating the result that he has achieved. In fact, "Surveys from industry consistently indicate that employers are looking for a workforce that has problem-solving and communication skills" (Brahier, 2016, p. 30), both of which are implicit in the implementation of modelling in a socially orientated classroom. Lizzy had no training as a teacher and we came to the conclusion that the importance of mathematical modelling in the classroom was something that had never come across her path. It was clear to us that the other three teachers were cognisant of the importance of bringing real-life contexts into the mathematics classroom, but that knowledge of how to exploit such contexts fully and successfully was lacking, except in the case of Cynthia. So while there was a will, there was generally little knowledge of how to accomplish it. According to Kaiser (2014), the modelling process involves "complex cognitive activities" (p. 404) and therefore scaffolding may especially be appropriate. However, "scaffolding has to be based on a diagnosis of students' understanding of the learning content which most teachers did not ascertain" (Kaiser, 2014, p. 396). We posit that ML teachers provide limited scaffolding since their diagnosis of the students' understanding, to which Blum (2002) refers, is flawed by their own lack of understanding of the modelling process. We also propose a fourth category to Schukajlov's framework: intramathematical problems with contextual illustration.

This brings us back to the request of our student teacher that made us think about modelling in ML classes. His concern was that the context was unfamiliar to the students and the mathematics applied to it did not make sense. Our research confirmed to us that the contextual problem must engage the learners in terms of their thinking and speaking and doing, but this does not necessarily mean that the context must be familiar. In fact, the DBE (2011) requires that the contexts should be both familiar and unfamiliar, but more than that, they should increase in demand and inaccessibility, to ensure progression as learners move from Grade 10 to Grade 12. We found that not only were the learners often not engaged, but that they resisted the mathematisation process and mostly just wanted to get to the actual sums without considering anything contextual.

The problem, as we observed, lies both in the context itself and in the mathematisation thereof. It would seem that teachers find it difficult to go beyond intra-mathematical problems to dressedup problems and finally to modelling problems. At the same time the modelling process seems unclear to them and the function and direction of mathematisation are not necessarily understood. The majority of the teachers who participated in our study mostly did not carry out this process, nor did they generally seem to fully appreciate the purpose of mathematisation as being useful for making content relevant to the learners. We found that the resistance to the use of real-life contexts in the ML classroom was based on disinterest in the context itself or an inability to relate to the real-life situation that was the subject of the intended mathematisation. 


\section{RECOMMENDATION}

Our study was initiated through the need to make pre-service mathematics teacher training relevant and useful to the students for their own future classrooms. We therefore use our conclusions to make recommendations for the practice of mathematics teacher training. Although in-service teacher training is vital, it is during pre-service teacher training where significant professional development can be encouraged to enable the novice teachers to enact a contextualised ML curriculum. Our investigation points to the fact that simply implementing mathematisation in the teaching of mathematics to student teachers does not necessarily equip them to carry out the process of mathematisation successfully in their own future classrooms. The process itself needs to be taught systematically. In addition to this, we agree with Stillman (2012) who says that the teachers' understanding of how learners approach modelling will contribute to "teacher planning and task design, in particular the identification of prerequisite knowledge and skills, preparation for intervention at keys points if required, and scaffolding of significant learning episodes". In order to provide student teachers with the necessary skills which will allow them to understand their future learners' thinking in the modelling process, their own understanding will have to be enhanced through scaffolding of "significant learning episodes" in their own undergraduate studies.

Aspects that should be addressed are the choice of modelling problems and working through the modelling process with particular reference to horizontal mathematisation. Facilitation by means of effective questioning on different levels should be practised where teachers use learners' thinking to provide scaffolding for their instruction. It is therefore essential that teachers be encouraged and shown how to assist learners in implementing the mathematical skills and knowledge that they have in order to mathematise their own realities.

\section{REFERENCES}

Biccard, P., \& Wessels, D. C. J. (2011). Documenting the development of modelling competencies of grade 7 mathematics students. In G. Kaiser, W. Blum, R. Borromeo Ferri and G. Stillman (Eds.). Trends in teaching and learning of mathematical modelling (pp. 375-384). New York: Springer.

Biccard, P., \& Wessels, D. C. J. (2017). Developing mathematisation practices in primary mathematics teaching through didactisation-based teacher development. African Journal of Research in Mathematics, Science and Technology Education, 21(1), 61-73.

Blum, W. (2002). ICMI study 14: Applications and modelling in mathematics education discussion document. Educational Studies in Mathematics, 51, 149-171.

Brahier, D. J. (2016). Teaching Secondary and Middle School Mathematics. New York: Routledge.

Brown, B., and Schäfer, M. (2006). Teacher education for mathematical literacy: A modelling approach. Pythagoras, 64, 45-51.

Cai, J., Cirillo, M., Pelesko, J. A., Borromeo Ferri, R., Borba, M., Geiger, V., Stillman, G., English, L..D., Wake, G., Kaiser, G., \& Kwon, O. N. (2014). Mathematical modeling in school education: mathematical, cognitive, curricular, instructional and teacher 
education perspectives (pp. 145-172). Proceedings of the joint meeting of PME 38 and PME-NA 36, PME-NA, Vancouver, Canada.

Cirillo, M., Pelesko, J. A., Felton-Koestler, M. D., \& Rubel, L. (2016). Perspectives on modelling in school mathematics. In C. R. Hirsch and A. R. McDuffie (Eds.). Annual perspectives in mathematics education 2016: Mathematical modelling and modelling mathematics (pp. 3-16). Reston: NCTM.

Department of Basic Education (DBE) (2011). Curriculum and assessment policy statement (CAPS). Mathematical Literacy. Retrieved from http://www.thutong.DBE.gov.za. Accessed 23 July 2016.

Freudenthal, H. (1973). Mathematics as an educational task. Dordrecht: Reide.

Freudenthal, H. (1991). Revisiting mathematics education. China Lectures. Dordrecht: Kluwer.

Gellert, U. (2004). Didactic material confronted with the concept of mathematical literacy. Educational Studies in Mathematics, 55, 163-179.

Gravemeijer, K.P.E. (1994). Developing realistic mathematics education. Utrecht: CD Press, Freudenthal Institute.

Jablonka, E. (2003). Mathematical literacy. In A. J. Bishop, M. A. Clements, C. Keitel, J. Kilpatrick and F. K. Leung (Eds.). Second Handbook of Mathematics Education (pp. 75102). Dordrecht: Kluwer.

Kaiser, G. (2014). Mathematical modelling and applications in education. In S. Lerman (Ed.). Encyclopedia of mathematics education (pp. 396-404). London: Springer.

Kaiser, G., \& Sriraman, B. (2006). A global survey of international perspectives on modelling in mathematics education. Zentralblatt für Didaktik der Mathematik, 38(3), 302-310.

Polya, G. (1957). How to solve it. Princeton, NJ: Princeton University Press.

Rosa, M., \& Orey, D. C. (2015). A trivium curriculum for mathematics based on literacy, matheracy, and technoracy: an ethnomathematics perspective. Zentralblatt für Didaktik der Mathematik, 47, 587-598.

Schoenfeld, A.H. (1983). What Makes for Powerful Classrooms, and How Can We Support Teachers in Creating Them? A Story of Research and Practice, Productively Intertwined. Educational Researcher, 43(8), 404-412.

Schukajlow, S., Leiss, D., Pekrun, R., Blum, W., Muller, M., \& Messner, R. (2012). Teaching methods for modelling problems and students' task-specific enjoyment, value, interest and self-efficacy expectations. Educational Studies in Mathematics, 79(2), 215-237.

Skovsmose, O. (2014). Mathematization as social process. In S. Lerman (Ed.). Encyclopaedia of Mathematics Education (pp. 441-445). London: Springer.

Stacey, K. (2011). The PISA View of Mathematical Literacy in Indonesia. Journal of Mathematics Education, 2(2), 95-126.

Stillman, G. (2012). Applications and modelling research in secondary classrooms: What have we learnt? Retrieved from http://www.acu.edu.au/_data/assets/pdf_file/0006/462948/Gloria_Stillman_-_ICME__Regular_Lecture.pdf. Accessed 16 August 2017.

Treffers, A. (1978). Wiskobas Doelgericht. (Wiskobas Goal directed). Utrecht: IOWO.

Zuga, K. F. (1992). Social reconstruction and technology education. Journal of Technology Education, 3(2), 48 - 58. 